La obra de Julio Cortázar, marcada por la experimentación narrativa y la búsqueda metafísica, no encajaba a priori en el patrón de la literatura realista al servicio de una sociedad socialista que se imponía oficialmente en la URSS. Sin embargo, sus escritos empezaron a traducirse al ruso ya en 1970. En este estudio se propone observar el mecanismo de la introducción y consagración de la obra cortazariana en el campo literario soviético -fuertemente condicionado por el poder estatal-, así como el doble papel de la crítica literaria que representaba tanto una herramienta de violencia simbólica del Estado como una forma de resistencia de los editores y mediadores culturales a esta última.

PALABRAS CLAVE: Cortázar, traducción, violencia simbólica, ideología, campo literario soviético.

\title{
El rol de la ideología en la consagración de la obra de Julio Cortázar en la URSS
}

EKATERINA EREMINA
The role of ideology in the canonization in the USSR of Julio Cortázar's literary work

The literary production by Julio Cortázar, featuring narrative experiments and a metaphysical quest, a priori did not fit into the dominant poetics of realistic literature at the service of socialism officially imposed in the USSR. However, his texts were translated into Russian from the beginning of the 1970s. This paper studies the mechanism of the introduction and canonization of Cortázar's writings in the Soviet literary field, highly conditioned by the state power, as well as the double role of literary criticism which served both as a tool of symbolic violence used by the State and as a form of resistance against it, adopted by editors and cultural mediators.

KEY WORDS: Cortázar, translation, symbolic violence, ideology, Soviet literary field. 


\section{INTRODUCCIÓN}

En la URSS el régimen comunista buscaba reforzar su poder, legitimándolo a nivel simbólico. Desde sus comienzos, la ideología soviética prometía un futuro utópico en un nuevo mundo y proponía forjar a un nuevo hombre con valores marxistas, fomentando una nueva manera de pensar a través de la política cultural'. La política cultural implicaba el control estatal tanto sobre la educación y la ciencia como sobre la literatura nacional y traducida.

Dicha política cultural puede ser vista como una potente herramienta de violencia simbólica, noción teorizada por Pierre Bourdieu (r996: I90) como el poder de producir a los agentes dotados de esquemas de percepción y de apreciación que les permitieran percibir las órdenes inscritas en una situación o un discurso y obedecerlas. La violencia simbólica del Estado soviético tenía por objetivo hacer que los imperativos del Estado se percibieran como evidentes y naturales, debido al hecho de que era el Estado mismo el que imponía las estructuras cognitivas que se le aplicaban.

En el marco del presente estudio analizamos el impacto del campo de poder en el campo literario soviético (en el sentido de Bourdieu, I991; I992) y sus productos no como una fuerza restrictiva sino en el sentido foucaultiano de la fuerza que produce saber y discurso (Foucault, I980). En concreto, el control estatal en el ámbito de la traducción y circulación de literatura importada, en la Unión Soviética, se manifestaba no tanto en forma de censura

I La política cultural soviética con respecto a la literatura fue vivamente expresada en la resolución del Comité Central del Partido Comunista de la Unión Soviética «Sobre la política del partido en el ámbito de las bellas letras» [«O политике партии в области художественной литературы»] de 1925 . directa, como en la centralización del campo editorial e imposición de disposiciones ideológicamente afines a los habitus de los agentes implicados (es decir, su estructura mental). La literatura traducida, después de I966, ya no se sometía a control preventivo de la Glavlit ${ }^{2}$ y las decisiones sobre la publicación o no publicación de una obra pasaron a manos de los editores. Al mismo tiempo, a partir de los años ı96o, la Glavlit organizaba reuniones con los editores y redactores jefe para explicarles las exigencias de la censura, fomentando la autocensura incorporada en sus habitus. Los editores, que a partir de 1969 respondían personalmente por las obras publicadas, conocían las reglas del juego, que definen las restricciones y los recursos dentro del campo, y los límites de lo publicable. Grosso modo, tres aspectos clave definían el destino de la obra importada en el espacio social soviético: la postura política de su autor, su tema y contenido y su poética. Los autores de izquierdas tenían más posibilidades de aparecer en las librerías y bibliotecas soviéticas. Asimismo, se daba preferencia a las obras de contenido social, que criticaban el mundo capitalista y el imperialismo estadounidense. En cuanto a la poética, las obras con innovaciones estilísticas o narrativas no tenían acceso fácil al lector soviético.

Según la teoría de la manipulación del canon literario del traductólogo André Lefevere (I992), los editores, críticos, traductores, profesores, que controlan el sistema literario desde dentro y actúan como guardianes de su poética e ideología, pueden escoger adaptarse al sistema y respetar sus límites, u oponerse al orden establecido. El investigador observa que, en la mayoría

2 Glavlit [Главлит] es el órgano oficial de la censura soviética cuya abreviatura entre los años I966 y I99i se descifraba como Dirección general de la protección de secretos estatales en la imprenta [Главное управление по охране государственных тайн в печати]. 
de los casos, estos profesionales no reprimen las obras de arte controvertidas, sino que las adaptan a la ideología y poética para que sean aceptables para el lugar y tiempo determinados (ib.: I4). Tal adaptación significa la creación de un cierto constructo o imaginario de la obra en las mentes de los lectores no profesionales ( $i b$ : 6). Este constructo se crea en parte debido a la labor de los reescritores (traductores, editores, filólogos, críticos literarios), profesionales del sistema literario que presentan la obra al lector y la inscriben en la cultura meta por medio de la edición, antología, historiografía, crítica literaria y traducción.

En este estudio nos centramos en los diferentes tipos de reescritura de la obra innovadora del escritor argentino Julio Cortázar (I9I4-I984) como mecanismo de su consagración en la URSS. La actualidad del tema radica en la escasez de los estudios que tratan la traducción, publicación o recepción de los autores hispanoamericanos en la Rusia soviética. Al mismo tiempo, precisamente las reescrituras de estos autores, a menudo de izquierdas (por ende, bienvenidos en la URSS) y poéticamente innovadores (un rasgo reprochable en el espacio soviético), son especialmente reveladoras para entender las reglas del juego y la plasticidad del campo literario soviético de los años I960-I980.

\section{EL ACTIVISMO POLÍTICO DE JULIO CORTÁZAR COMO PRETEXTO PARA SU CONSAGRACIÓN EN EL CAMPO LITERARIO SOVIÉTICO}

En el espacio social soviético el nombre de Cortázar aparece por primera vez en la prensa periódica, y no en librerías o revistas literarias como se podría suponer. La primera mención la encontramos en una nota sobre el Congreso de los Escritores de América Latina en Chile publicada en el número de Literaturnaya gazeta [Periódico literario] del 27 de agosto de I969. Esta referencia a Cortázar como escritor destacado es anterior a su primera traducción al ruso o crítica literaria, y el subtexto ideológico de la nota (Medvedenko, I969) no es anodino.

Para explicar esta introducción de un escritor ya consagrado en el resto del mundo por su compromiso social, se debe recordar el ávido interés político de la Unión Soviética hacia los países de América Latina, despertado por la Revolución cubana (1959). La presentación de América Latina como un conjunto de países de revoluciones socialistas donde los obreros e indígenas oprimidos luchan contra los dictadores y el imperialismo estadounidense contribuía a la consolidación de la metanarrativa (Lyotard, 1979) comunista dentro del país. Además, reforzando las relaciones con los escritores latinoamericanos, el Estado soviético aspiraba a atraer a su lado a los intelectuales de izquierda y convertir Moscú en la capital del comunismo universal (Baer, 20I6: 6I).

Por lo cual no es de extrañar que el nombre del escritor argentino apareciera a menudo en las páginas de la prensa soviética, siempre con la mención de su compromiso político. Así, en mayo de 1979, Literaturnaya gazeta nos informa de que Cortázar participó en el Foro internacional de solidaridad con la cultura chilena que tuvo lugar en Toruń, Polonia (Sherbakov, 1979). La entrevista concedida por Cortázar a Evgueni Evtushenko fue anunciada en Literaturnaya gazeta con una frase que ponderaba el compromiso político del escritor: «Позиция Кортасара - это бескомпромиссное служение идеалам социализма не только словом, но и действием» [La postura de Cortázar -es un servicio intransigente a los ideales del socialismo no sólo con la palabra sino también con la acción] (Literaturnaya 
gazeta, I980: 15)3. En el texto de la entrevista se planteaban cuestiones que eran de interés para el discurso oficial soviético y que provocaban réplicas de Cortázar como «я верю в лежащий перед Латинской Америкой исторический путь социализма» [creo en el camino de socialismo que aguarda América Latina], «я убежден, что социализм - единственная философская система, опирающаяся на оптимизм, на сознание того, что человечество может стать счастливым» [estoy convencido de que el socialismo es el único sistema filosófico que se basa en el optimismo, en la conciencia de que la humanidad puede hacerse feliz], «капитализм, дьявольское изобретение, оживающий мертвец» [el capitalismo, la invención diabólica, un cadáver resucitado].

En I984 un reportero de Izvestia [Noticias] destaca que Cortázar no solo era uno de los autores latinoamericanos más talentosos sino también un ardiente luchador por la independencia y la soberanía de los países de América Latina (Bai, I984: 4) y el mismo año el periódico Pravda (1984) cita a Cortázar para reforzar su acusación a los Estados Unidos del «удушении» [estrangulamiento] de Nicaragua. Otra cita del escritor a propósito de Nicaragua vuelve a aparecer en Pravda en I985:

Неужели мы оставим Никарагуа в одиночестве в этот час? Разве мы позволим, чтобы прибивали к кресту ее руки и ноги, и чтобы какой-то наглый проконсул продолжал играть остальным миром во имя "мира по-североамерикански"? [¿Vamos a dejar sola a Nicaragua en esta hora que es como su Huerto de los Olivos? ¿Dejaremos que le claven las manos y los pies para que un insolente procónsul siga jugando con

3 Todas las traducciones, salvo indicación contraria, son propias. el resto del mundo en nombre de una pax... norteamericana?4] (Korionov, I985: 5)

Con estas publicaciones, que podemos calificar de reescrituras por la historiografía, la prensa periódica soviética creaba el imaginario de Cortázar como un activista fuertemente comprometido con la causa socialista. Efectivamente, el primer viaje del escritor a Cuba en I963 dio inicio a un compromiso político que Cortázar no abandonará hasta su muerte. El escritor apoyó la Revolución cubana y la Nicaragua sandinista, así como al Chile de Allende, y participó en la investigación de los casos de desaparecidos en Argentina, Uruguay, Chile, Guatemala y El Salvador. Entre otras cosas cedió los derechos de autor de varios de sus libros: los del Libro de Manuel al Sindicato de los Gráficos de Argentina, de los Fantomas contra los vampiros multinacionales al Tribunal Russell, de Los autonautas de la cosmopista (tanto en su edición española como francesa) y de Nicaragua tan violentamente dulce al pueblo sandinista de Nicaragua.

Sin embargo, es seguramente excesivo hablar de un compromiso político incondicional de Cortázar, tal y como este se representaba en las fuentes rusas de la época soviética y en las revistas socialistas como Cuadernos de Cultura, Casa de las Américas, Bohemia, Revista Nacional de Cultura o Granma, utilizados por los filólogos soviéticos como fuente de información y crítica literaria. Cortázar nunca aceptó la calificación de militante comunista que le intentaron dar algunos medios de comunicación y veía las controversias y peligros del régimen castrista. El escritor firmó la primera carta a Fidel en la cual los escritores le pedían explicaciones acerca del arresto del poeta Padilla, el primer

\footnotetext{
4 Texto original citado según «De diferentes maneras de matar».
} 
indicio que reveló la problemática situación de los intelectuales en Cuba. Aunque Cortázar seguía creyendo en los valores positivos de la Revolución cubana aun después de la revelación del caso Padilla, al mismo tiempo se oponía a sus aspectos negativos (Cortázar, 2000: vol. 3, 1456). Su solidaridad era crítica y no «una obediencia ciega como algunos cubanos pretenden de nosotros» (ib.: I462).

El autor destacaba sobre todo los riesgos del comunismo a lo soviético: «El gran peligro en Cuba (y Castro, el Che Guevara y la mayoría de los intelectuales lo saben) es el comunismo 'duro', de corte stalinista» (Cortázar, 20I2: vol. 2, 355). Se opuso a las acciones de la URSS en Checoslovaquia en 1968, firmó cables y mensajes de protesta al respecto e incluso pasó ocho días en Praga invitado por la Unión de Escritores. En 1968, Julio Cortázar, Gabriel García Márquez y Carlos Fuentes tomaron un tren de París a Praga «con la buena intención de salvar lo insalvable: la primavera del socialismo con rostro humano» (Fuentes, 2004).

En los archivos GARF (Archivo Estatal de la Federación Rusa) ${ }^{5}$ y RGALI (Archivo Estatal Ruso de Arte y Literatura $)^{6}$ y en las entrevistas o autobiografías de los agentes del campo literario apenas hemos encontrado ninguna constancia del contacto de Cortázar con la URSS. Aparte de un breve encuentro en un ascensor con la traductora Margarita Bylínkina y entrevistas concedidas al poeta Evgueni Evtushenko y al periodista Sergéi Márkov en la Habana, solo nos consta su rechazo a redactar un artículo sobre la cultura en Nicaragua para la revista del Instituto de América Latina (Cortázar, 1984: I04). A diferencia de García Márquez o

\footnotetext{
5 ГАРФ (Государственный архив Российской Федерации).

6 РГАЛИ (Российский государственный архив литературы и искусства).
}

Vargas Llosa, Cortázar nunca viajó a la Unión Soviética. Sin embargo, su intensa actividad social permitió a los críticos literarios soviéticos presentar al Cortázar tardío como un escritor comprometido con los valores del comunismo y legitimar de esta manera la importación de obra cortazariana en la URSS. Lo que fue hecho mediante las reescrituras (Lefevere, 1992) que creaban un imaginario de Cortázar que se adaptaba a la ideología dominante y podía ser aceptado en el campo literario soviético.

\section{LA TRADUCCIÓN Y PRESENTACIÓN DE LAS OBRAS DE JULIO CORTÁZAR EN LA URSS}

La obra de Julio Cortázar, marcada por la experimentación narrativa y la búsqueda metafísica, no encajaba a priori en el patrón de la literatura realista al servicio de una sociedad socialista que se imponía oficialmente en la URSS hasta la perestroika ${ }^{7}$. Sin embargo, sus libros poéticamente ajenos al realismo socialista empezaron a traducirse al ruso en 1970. Mientras que en el resto del mundo se puede hablar de la consagración de Cortázar a partir de la publicación de Rayuela en r963 (Rama, I981: 88), en la Unión Soviética sus obras no aparecieron hasta siete años más tarde y en gran medida gracias a mediadores culturales como Ella Braguinskaya y Margarita Bylínkina. En su mayor parte fue el compromiso político de Cortázar el que justificó la aparición de sus obras en el campo literario soviético, ya que permitía a los editores publicarlas al amparo de las entrevistas, discursos y cartas de pathos socialista del escritor

7 La perestroika [перестройка] fue una política de reformas estructurales que empezó a implementarse paulatinamente en la URSS tras la llegada al poder de Mijaíl Gorbachov (I985-I99I) y que implicaba la liberalización del mercado, el pluralismo político y la transparencia informativa. 
y de los prefacios ideológicamente afines. Las críticas literarias soviéticas proponían una reescritura del imaginario de Cortázar y su obra, ponderando el compromiso político del autor, el estilo realista de su prosa y el subtexto social en la temática de las obras.

E1 proceso de la reescritura continuaba con una edición muy selectiva de los textos traducidos, que se hacía según las reglas del juego del campo literario soviético. Dada la centralización máxima del campo editorial, solo un número limitado de editoriales, todas ellas públicas, tenían derecho a publicar la literatura extranjera. Así fueron Judózhestvennaya literatura [Literatura de ficción], la principal editorial soviética en materia de literatura de ficción en los años I960-I980; la revista Inostrannaya literatura [Literatura extranjera], nominalmente fundada durante la época del deshielo y una de las principales fuentes de literatura extranjera contemporánea, con foco en las obras no traducidas anteriormente y publicadas en los últimos años, en los años 1950-I980; y la revista especializada Latinskaya América [América Latina], fundada en 1969 y dedicada a la política, cultura, economía, etc. de los países de América Latina, las que editaron la mayor parte de las traducciones de obras hispanoamericanas publicadas en la época soviética. $\mathrm{El}$ análisis de los archivos de estas editoriales permite entrever el complejo mecanismo de la reescritura y adaptación del canon de la obra cortazariana al contexto soviético.

Ya en I967 la revista Inostrannaya literatura contemplaba la posibilidad de traducir varios relatos de Cortázar. El interés del equipo editorial fue suscitado por la noticia en la revista argentina Marcha sobre los planes de la editorial Siglo XXI de publicar la obra del escritor. El artículo, traducido al ruso para el uso interno de Inostrannaya literatura, afirmaba que el hecho de que la editorial mexicana estuviera dirigida por Arnaldo Orfila Reynal significaba la garantía de «успеха, высокого интеллектуализма и правильной идеологической ориентации» [éxito, nivel intelectual alto y correcta orientación ideológica] (RGALI, I966). En los archivos del año siguiente ya encontramos las fichas de lectura de los relatos «Circe» (I95I), «Final del juego» (1956), «La noche boca arriba» (1956), «Las babas del diablo» (1959), «Cartas de mamá» (1959), «El perseguidor» (I965) y «La autopista del sur» (I966) en las que se valoraba su posible traducción. Su autor, Timoféi Kúrochkin, intenta presentar los relatos en el marco de la poética del realismo, que ocupaba una posición dominante en el campo literario soviético. $\mathrm{Al}$ comentar la forma del conjunto de los cuentos, en su mayoría fantásticos, afirma que los elementos de imaginación y de índole fantástica se entrelazan de manera natural con el realismo (RGALI, I967: I). El relato «La autopista del sur» recibe una interpretación cuasi socialista:

Голод и жажда, вызванные длительной и непредвиденной остановкой, заставляют людей объединиться в какой-то коллектив с определенным распределением труда. $<\ldots>$ Перед лицом общего несчастья люди проявляют благородство и мужество, товарищество и солидарность. [E1 hambre y la sed, provocados por una parada larga e imprevista, hace que la gente se una en una especie de colectivo con cierta división de trabajo. $\langle\ldots\rangle$ Frente a una desgracia común la gente muestra magnanimidad y valentía, camaradería y solidaridad.] (ib.: 2 )

A modo de conclusión, Kúrochkin recomienda la traducción de varios relatos de Cortázar. No obstante, como el informe no contenía ninguna referencia al incipiente compromiso político de Cortázar ni un análisis de los textos como una 
crítica a la sociedad capitalista, no convenció al equipo editorial, que decidió no publicarlos.

$\mathrm{Al}$ año siguiente, la revista volvió a plantearse la posibilidad de traducir la obra de Cortázar. En sus archivos de 1968 encontramos dos informes internos con reseñas de Los premios. Los dos críticos que prepararon las fichas de lectura de esta novela para Inostrannaya literatura propusieron análisis completamente diferentes. Kúrochkin, quien había recomendado la publicación finalmente no aprobada de los cuentos de Cortázar, criticó la novela. En su informe afirma que la traducción y edición en ruso de Los premios sería inconveniente (RGALI, 1968: 9). El crítico lo argumenta aludiendo a las abundantes escenas eróticas y a la descripción de perversiones que contiene el texto de la obra $\mathrm{y}$ concluye que

Указанные несоответствия содержания романа с существующими у нас нормами приличия не компенсируются в нем такими литературными достоинствами, которые, несмотря ни на что, делали бы вопрос о целесообразности публикации романа в СССР дискуссионным. [El evocado incumplimiento del contenido de la novela con nuestras normas de decencia no se compensa por las cualidades literarias que hicieran posible - a pesar de todo- una discusión sobre la utilidad de la edición de la novela en la URss.] (ib.)

El segundo informe difiere radicalmente del análisis de Kúrochkin. El autor del documento, Venedict Vinográdov, ve en la novela una crítica ácida de la sociedad burguesa, y destaca la lograda descripción de la psicología de los personajes у «художественная выразительность произведения» [«la expresividad artística de la obra] (ib.: 15). Aunque Vinográdov recomienda la publicación de Los premios, el primer informe negativo frenó la traducción de la novela.
Cortázar debutó en el campo literario soviético en 1970 con dos relatos: «El perseguidor» (1965) y «La autopista del sur» (1966) — cuya publicación había sido descartada en I967aparecieron en el número I de 1970 de la revista Inostrannaya literatura, en traducción y con prefacio de Bylínkina ${ }^{8}$, mediadora cultural que desempeñó un papel importante en la consagración de Cortázar en la URss. Por un lado, debido a su historia familiar tenía un habitus propicio a la resistencia contra el discurso comunista dominante. Por el otro, debido a la naturaleza de su trabajo en Inostrannaya literatura y luego en el Instituto de América Latina, viajes a Argentina, Cuba y México (Bylínkina, 2005), su babitus poético estaba influido por Occidente.

La trascendencia de esta traductora en las publicaciones rusas de Cortázar merece una mención aparte. Bylínkina (2005: 279-28I) conoció a Cortázar en la Habana. En su autobiografía la traductora cuenta que después de una breve conversación en el ascensor del Congreso Cultural de I968 Cortázar le entregó un libro con su relato «El perseguidor» y le pidió que le contara luego sobre el destino de ese texto en Rusia. En esta obra precursora de Rayuela -Cortázar solía llamarla rayuelitael lado fantástico, que caracterizaba las obras de la primera etapa estética del escritor, queda en segundo plano, dando lugar a las búsquedas metafísicas del protagonista, el músico de jazz Charlie Parker, descrito bajo el nombre de Johnny Carter. Tal y como hará después Oliveira en Rayuela, Johnny desconfía de los moldes y órdenes preestablecidos y cuestiona la percepción convencional del tiempo. Ni el tema ni el estilo del relato presagiaban su traducción al ruso; al menos, no sin intervención de un

8 Lamentablemente, los documentos que acompañaron esta publicación no se conservaron en los archivos, pero suponemos que Bylínkina actuó de mediadora cultural. 
mediador que conociera bien las reglas del juego del campo literario soviético. En su autobiografía, Bylínkina afirma que fue este relato el que «упрочил славу Кортасара как рассказчика за рубежом, а у нас, по сути дела открыл его читателям» [en el extranjero fortaleció la fama de Cortázar como narrador y en nuestro país, en el fondo, descubrió su obra al lector] (ib.: 28r).

En aquel prefacio que acompañaba la primera traducción rusa de Cortázar se destaca la búsqueda social-filosófica y estético-literaria de Cortázar y se subraya que la respuesta en el primer caso es «социализм Маркса» [el socialismo de Marx], y en el ámbito literario — «явно реалистическое направление» [una tendencia marcadamente realista] (Bylínkina, I970: 7). Además, la traductora insiste en el subtexto de crítica anticapitalista de los relatos, al afirmar que uno de los temas principales en la obra del escritor argentino es «разобщенность людей, духовная одинокость человека в капиталистической среде» [la desintegración de la gente, la soledad espiritual de una persona en el ambiente capitalista] (ib.). Suponemos que este prefacio, más que la propia traducción, sentó el precedente para las futuras traducciones de Cortázar.

Unos meses más tarde, en el número de febrero de 1971 de la revista Latinskaya América, se publicó otra traducción de Cortázar hecha por Bylínkina. Se trataba de los textos de Material plástico (I962), acompañados del prefacio crítico de la traductora que presentó estos textos como fábulas dirigidas contra los regímenes dictatoriales en América Latina, el imperialismo norteamericano y el sistema burocrático burgués (Bylínkina, 1971: 130). Asimismo, dedicó la mayor parte del prefacio al tema del compromiso político de Cortázar y su fe en las revoluciones socialistas, describiendo los textos de Material plástico como «его работа на революцию, против уродливых сторон жизни капиталистического общества» [su trabajo por la revolución, contra los aspectos feos de la vida de una sociedad capitalista] (ib.: I33).

En el mismo lapso temporal - del 8 de mayo de r969 al I5 de febrero de I97I, según los archivos (RGALI, I97Ib)—, Bylínkina participó en la preparación de la recopilación de relatos publicada en la editorial Judózhestvennaya literatura con una edición de Braguinskaya. Según los documentos internos de dicha editorial, la edición de 75.000 ejemplares estaba dirigida a «массового читателя» [un lector de masas] (ib.: I). La lista original, propuesta por Braguinskaya, fue criticada en el informe interno de Serguéi Zméev del 26 de agosto de 1969. Zméev insistía en la necesidad de incluir los relatos «Reunión» - por el gran interés que mostraba el escritor por la Revolución cubana- $\mathrm{y}$ «La isla al mediodía», y de excluir «La Señorita Cora», «Las Ménades» y «Los buenos servicios» por ser superficiales y demasiado sentimentales (ib.: 18). E1 30 de septiembre de 1969 Bylínkina propuso incluir «El perseguidor», que, según la traductora, reflejaba la soledad espiritual de un gran artista en la sociedad burguesa contemporánea, y las miniaturas de Material plástico, donde «мастерски показаны отдельные стороны капиталистической действительности» [están magistralmente mostrados ciertos aspectos de la realidad capitalista] (ib.). La justificación fue escrita según las reglas del juego dentro del campo literario soviético y permitió incluir estos textos en la recopilación. La reunión del equipo editorial que aprobó la lista definitiva tuvo lugar el 2 de octubre de 1969 . En la reunión, que contó con la participación de Ella Braguinskaya, Valeri Stólbov, Nicolái Tomachevski y Margarita Bylínkina, esta última propuso incluir también los fragmentos de $\mathrm{His}^{-}$ torias de cronopios y de famas, pero el editor jefe, 
Stólbov, los definió como «raros». Fue después de la intervención de la editora de la recopilación, Braguinskaya — «Кортасар превосходный писатель, романы его очевидно переводиться у нас не будут, и мы разумеется должны представить его рассказы наиболее полно» [Cortázar es un excelente escritor, sus novelas aparentemente no van a traducirse en nuestro país, y evidentemente debemos presentar sus relatos de manera más amplia posible] (ib.) — cuando estos textos entraron en el plan editorial del libro. Esta cita revela que Braguinskaya consideraba que la complejidad de la narración en las novelas de Cortázar las hacía impublicables en el espacio soviético de los años setenta.

La versión final de la recopilación incluyó unos de los cuentos más representativos de los períodos estético y metafísico de Cortázar, tal como planteó Braguinskaya en la reunión editorial. Ambas propuestas de Bylínkina fueron aceptadas, mientras que la argumentación sobrepolitizada de Zméev para la exclusión de «La Señorita Cora» y «Las Ménades» y para la inclusión de «Reunión» no tuvieron efecto, aunque el relato sin referencias socialistas «La isla al mediodía» sí que fue incluido en el libro en traducción de Zméev. El libro salió en Judózhestvennaya literatura en 1971 y Cortázar se hizo rápidamente famoso entre la intelliguentsia soviética lectora (Veller, 2003: II7). Según Bagnó (I999: 5), a partir de la publicación del volumen y en el plazo de un mes por lo menos 1.000.000 personas - en su mayoría estudiantes- habían leído esos relatos.

La recopilación se publicó con prefacio de Braguinskaya. La historia de su redacción, que pudimos entrever en los archivos, es reveladora para entender las reglas del juego dentro del campo literario soviético. Originalmente el prefacio se titulaba «Rebelión de Cortázar» ${ }^{9}$ y el texto inicial pasó por una revisión interna de la editorial. La autora de la reseña del prefacio critica cinco aspectos del artículo de Braguinskaya: la interpretación de la rebelión del escritor como lucha contra los valores prefabricados por nuestra conciencia y no contra la visión burguesa del mundo; la insinuación del vínculo de la poética cortazariana con el existencialismo; la excesiva importancia concedida al humor; la alusión al carácter abierto de las obras de Cortázar; y la omisión del carácter realista del relato «El perseguidor» (RGALI: I97rb). Aunque solemos encontrar todos estos aspectos en la crítica literaria occidental dedicada a Cortázar, en el espacio comunista estos elementos contradecían la ideología y poética dominantes.

En el texto final Braguinskaya incorporó algunos cambios y descartó otros. En concreto, en el libro publicado, la rebelión de Cortázar ya no se interpreta como dirigida contra los valores creados por la razón humana y la lógica aristotélica. El título del prefacio es más neutro que en la versión inicial y se lee como «Julio Cortázar y sus relatos» ${ }^{10}$. La crítica señala que «Кортасар не принимает буржуазной реальности c еe набором фарисейских традиций» [Cortázar no acepta la realidad burguesa con su conjunto de tradiciones hipócritas] (Braguinskaya, I971: 9) y observa que el humor de Cortázar es irónico y triste y revela la necesidad de luchar contra los fantasmas y dogmas de las famas y esperanzas burguesas (ib.: 15$)$. «El perseguidor» también resulta interpretado, según la recomendación del revisor, como un relato realista. Al mismo tiempo, Braguinskaya conserva la alusión al existencialismo y propone ver la rebelión de los personajes de Cortázar no solo como una insu-

9 «Бунт Кортасара».

го «Хулио Кортасар и его рассказы». 
bordinación contra los valores burgueses, sino contra todo lo impuesto desde fuera.

En general, aunque Braguinskaya menciona tanto la actividad social de Cortázar, representándole como amigo de Cuba, el Che Guevara y el Chile de Allende, crítico con la guerra de Vietnam, como su crítica a la vida burguesa y el realismo en su obra, no se puede decir que la ideología guíe la redacción del prefacio. De hecho, el texto de Braguinskaya subraya la relatividad de la interpretación de la figura del propio Cortázar, que puede ser descrito como un revolucionario comprometido o que puede ser reprochado por su indiferencia hacia los «intereses palpitantes de la vida» (Braguinskaya, I97I: 6). Si se compara el prefacio de Braguinskaya con los paratextos occidentales, se pueden observar bastantes más puntos en común que los que presentan otros paratextos de la época soviética. Cabe mencionar que este parece ser el único ${ }^{\text {II }}$ prefacio de Braguinskaya publicado antes de la perestroika. Asimismo, después de I971 podemos constatar una pequeña pausa de cinco años en la traducción al ruso de las obras cortazarianas.

Durante este lapso en el que se aprecia una

II Entre paréntesis podemos mencionar aquí otro artículo crítico que, a pesar de representar un análisis detallado y riguroso, no se cita en ninguna otra fuente de la época soviética. Se trata del estudio del investigador Yuri Pokalchuk, publicado en 1978 en la revista especializada Latinskaya América. Tanto por el carácter del análisis como por las alusiones a la obra de Franz Kafka, Thomas Mann, Herman Hesse, Robert Musil, Johan Huizinga y James Joyce, este estudio tiene muchos más puntos en común con la crítica occidental que con el resto de los textos filológicos de la época soviética. Suponemos que este estudio pudo publicarse debido a una menor presión de la censura sobre las revistas especializadas, que tenían una tirada limitada (en el caso de este número, 7.500 ejemplares). Además, este artículo fue publicado en las mismas páginas que un texto sobre Cortázar y Cuba. También es importante señalar que su autor era de Kiev, alejado del control estatal centralizado en Moscú. ausencia de traducciones, Inostrannaya literatura publicó en su sección de crítica literaria un artículo de la hispanista Inna Terterián (1974) dedicado a las novelas de Cortázar. El título del artículo, «E1 Hombre paradójico moderno» ${ }^{\mathrm{r}}$, remite a la obra de Dostoyevski. Aunque la filóloga insiste en el hecho de que Cortázar está atacando a la sociedad burguesa capitalista y de que apoya la actividad revolucionaria en los países latinoamericanos con medios económicos obtenidos gracias a la publicación del Libro de Manuel, el tono general del artículo es bastante crítico. Terterián constata la complejidad narrativa, la abundancia de sinsentido y el fracaso del experimento lingüístico de Cortázar en Rayuela y critica la ausencia de respuestas políticas concretas, la vacilación ideológica y la libertad sexual de los personajes en el Libro de Manuel. No es de extrañar que las novelas analizadas en este artículo crítico tardaran en traducirse al ruso y empezaran a publicarse pasados más de Io años, a partir de 1985 .

Sin embargo, Los premios - primera novela del período metafísico que presenta una aparente simplicidad narrativa y la posibilidad de interpretarla como una crítica de la sociedad burguesa- sí que se tradujo al ruso ya a finales de 1970. En 1976 la editorial Progres publicó un libro que contenía esta novela y varios relatos de Cortázar. La selección de relatos incluía los textos ya editados en I97I con la adición del cuento «Reunión», que podía ser leído como homenaje no solo al Che Guevara, al que alude el epígrafe del relato, sino también a Fidel Castro y la Revolución cubana. Además, la edición iba acompañada del prefacio de Lev Ospovat «Las búsquedas y descubrimientos de Julio Cortázar» ${ }^{13}$, donde el investigador afirma que

г2 «Новейший парадоксалист».

13 «Поиски и открытия Хулио Кортасара». 
el interés del gran cronopio por las revoluciones latinoamericanas empezó en la segunda mitad de los años cincuenta (Ospovat, I976: II-I2), lo que contradice los testimonios del propio Cortázar (2013), pero permitió legitimar la traducción al ruso de esta novela temprana del escritor, publicada en 1960, antes de aquel primer viaje a Cuba que marcó el inicio de su compromiso político.

Cabe mencionar que los textos críticos no solo acompañaban a las publicaciones ya aprobadas, sino que en algunos casos las revistas optaban por preparar la justificación ideológica con algún artículo crítico o un texto de índole política como paso previo a la traducción de varios relatos en el número siguiente. Así, en I978 la revista Inostrannaya literatura primero incluyó en su número 8 un texto crítico de Elena Ógneva dedicado al análisis de lo fantástico en la prosa de Cortázar y escrito acorde a la ideología comunista. Ógneva observa que en relatos como «La autopista del sur» $\mathrm{y}$ «Reunión» (ya traducidos al ruso) aparece un «коллективный герой» [personaje colectivo] (Ógneva, 1978: 265). Luego analiza varios relatos de Octaedro y Alguien que anda por allí y argumenta que, mientras el mal misterioso que opera en los cuentos fantásticos de Cortázar se concretiza en algo histórico-social, sus personajes están a punto de pasar de la contemplación pasiva a la acción (ib.). Después de esta reseña, en el número 9 se publicó la traducción de Bylínkina de «Los pasos sobre las huellas» $\mathrm{y}$ «Manuscrito hallado en un bolsillo» ${ }^{\mathrm{I}}$ de Octaedro.

Siguiendo el mismo patrón, en 1980, el periódico Literaturnaya gazeta publica primero en febrero una entrevista a Cortázar donde se destaca su compromiso político, y luego ya en

I4 En I98I estos relatos fueron reeditados por la editorial Molodaya gvardia dentro de una antología de prosa latinoamericana recopilada por la traductora. marzo la traducción del relato «Graffiti» de Octaedro, acompañado de un prefacio anónimo que destacaba la actividad social de Cortázar y su participación en los congresos socialistas.

La misma finalidad tenía la publicación de una elevada proporción de cartas, entrevistas y discursos de Cortázar dedicados a los aspectos relacionados con el socialismo y las revoluciones latinoamericanas, así como de relatos sobre esta temática. Por ejemplo, el cuento «Apocalipsis de Solentiname» —una vívida demostración del apoyo del escritor a las revoluciones socialistas en América Latina- se publicó dos veces entre 1979 y 1980. La tirada sumaria de Latinskaya América (7.500 ejemplares) y de Nedelia ${ }^{15}$ [Semana] ( 8.000.000 ejemplares) aseguraron una amplia divulgación del relato. La edición de Latinskaya América iba acompañada del prefacio de $Z$ méev donde el crítico hace hincapié en el recorrido de Cortázar como activista político. En las dos páginas del texto las cuestiones literarias ocupan tan solo dos párrafos, donde Zméev (1979: 184) subraya que el escritor comprendió que la literatura era un arma en la lucha de los pueblos de América Latina por una verdadera independencia.

Asimismo, en su número 4 de 1979 Inostrannaya literatura publicó el texto de la comunicación preparada por Cortázar para el Congreso del Pen Club en Montreal, titulada «El escritor y el lector bajo las dictaduras en América Latina». En 1982 Vera Kutéischikova y Lev Ospovat incluyen en su libro de textos sobre la literatura de autores de América Latina fragmentos de la entrevista que el gran cronopio concedió a Enrique González Bermejo y su carta a Fernando Retamar, que aparece bajo el título «Situación del intelectual latinoamericano» y donde el escritor afirma su solidaridad con la

15 «Неделя». 
causa socialista. A la evolución del compromiso político de Cortázar está dedicado el artículo de Terterián (I982a) «Las cenizas ardientes de una hoguera» ${ }^{16}$, publicado en septiembre en Literaturnaya gazeta como prefacio a dos textos de Un tal Lucas (I979) en traducción de Pável Grushkó: «Un pequeño paraíso» $\mathrm{y}$ «Cazador de crepúsculos». La hispanista destacaba el compromiso político del escritor, mencionando sus viajes a Cuba, su amistad con Salvador Allende y su participación en las acciones antimperialistas y «antidictatoriales» de la intelliguentsia latinoamericana progresista (Terterián, I982a: I5). La reseña concluye con una cita de la carta anteriormente mencionada de Cortázar a Retamar, donde el escritor afirmaba que el socialismo daba una visión práctica del arquetipo en el que culminaría la sociedad humana.

Las editoriales aprovecharon estas publicaciones que afirmaban la afinidad ideológica de Cortázar con la ideología dominante para publicar varios relatos sin referencias socialistas. En I982 la revista Inostrannaya literatura publicó en su número 5 las primeras traducciones de Cortázar a cargo de una joven traductora, Alla Borísova, que después del desplome de la URSS hará una retraducción de Rayuela. Se trataba de los relatos "Texto en una libreta», "Tango de vuelta», «Historias que me cuento» y «Clone» de Queremos tanto a Glenda (I980), que había traído de España su profesora y una de las figuras de referencia en la escuela de traducción de Leningrado, Aleksandra Koss (Borísova, 20I6). El mismo año, la editorial Molodaya gvardia reimprimió la traducción del cuento «Las Ménades» de Braguinskaya, cuya inclusión en la recopilación soviética de I97I fue reprobada por Zméev y cuya adaptación al cine fue censurada en la España de Franco.

I6 «Пылающий пепел костра».
E1 mismo mecanismo se observa en I984, cuando la revista Latinskaya América publicó la traducción del discurso (casi entero) que Cortázar había pronunciado al recibir la Orden de la Independencia Cultural «Rubén Darío». Inostrannaya literatura, a su vez, publicó unos fragmentos del discurso de Cortázar sobre la revolución en Nicaragua bajo el título «La revolución a la cual me unen vínculos de amor» ${ }^{17} \mathrm{y}$ en el número ro su discurso contra el apartheid. Estos textos tuvieron una amplia difusión en la URSS, dado que la tirada alcanzó los 377.000 ejemplares, y la revista aprovechó esta publicación de contenido político para editar una recopilación de relatos de Cortázar en la serie Biblioteca zhurnala Inostrannaya literatura ${ }^{18}$ [Biblioteca de la revista Literatura extranjera]. Este libro de relatos, que se publicó con una tirada de 50.000 ejemplares, incluía algunos exentos de subtexto socialista como «Continuidad de los parques», «Sobremesa» $\mathrm{y}$ «El móvil» de Final del juego (I956); "Instrucciones para John Howell» $\mathrm{y}$ «Todos los fuegos el fuego» del libro de cuentos homónimo (I966); «Liliana 1lorando», «Lugar llamado Kindberg» de Octaedro (I974); "La noche de Mantequilla» de Alguien que anda por alli (1977); "Orientación de los gatos» $\mathrm{y}$ "Queremos tanto a Glenda» del libro homónimo (I980); «Viaje a un país de cronopios» de Historias de cronopios y de famas (1962) y algunos textos de Un tal Lucas (I979).

Uno de los años clave para la consagración de Cortázar en la URss fue I984. Con motivo de la muerte del escritor el i2 de febrero de I984, Literaturnaya gazeta publicó «Queremos tanto a Glenda» en el número del is de febrero y «La escuela de noche» en el número del I9 de septiembre. La difusión de estos relatos

\footnotetext{
I7 «Революция, с которой меня связывают узы любви».

I8 «Библиотека журнала Иностранная литература».
} 
fue muy importante: la tirada alcanzó aproximadamente los 3.000.000 ejemplares. Ambos textos estaban acompañados de prefacios que imponían una lectura en línea con la ideología y poética dominantes. Otro prefacio de Terterián fue publicado por Literaturnaya gazeta en 1984 para acompañar la traducción de «La escuela de noche». La hispanista analiza el relato como «метафизическая анатомия» [una anatomía metafísica] (Terterián, I984a: 15) del fascismo, su ideología y sus métodos de manipulación de las almas humanas y subraya que el propio Cortázar estaba dispuesto a luchar contra el fascismo, el imperialismo y las dictaduras. El prefacio anónimo a "Queremos tanto a Glenda», igual que los textos de Terterián, subraya el compromiso político de Cortázar y presenta la obra como un cuento sobre «уродливом формировании психологии западной публики, питающейся суррогатом "массовой культуры”" [la monstruosa formación de la psicología del público occidental que se nutre del sucedáneo de la «cultura de masas»] (Literaturnaya gazeta, I984: 15).

También con motivo de la muerte de Cortázar apareció el artículo del escritor y comunista chileno Volodia Teitelboim que resultó crucial en la historia de la publicación en ruso de las novelas 62. Modelo para armar y Rayuela. Este escrito fue traducido en el número 8 de 1984 de la revista Inostrannaya literatura ${ }^{\mathrm{I} 9}$, donde su título simple («Julio Cortázar») se transformó en «Vías y esperanzas de Julio Cortázar» ${ }^{2}$. Teitelboim (I984b), que había conocido al gran cronopio personalmente, cuenta una serie de historias sobre su vida, y destaca sobre todo la actividad social del escritor: sus viajes a Cuba, el

I9 El texto original se publicó bajo el título «Julio

Cortázar» en el número de Casa de las Américas dedicado a Cortázar (NI45-I46, I984).

20 «Пути и надежды Хулио Кортасара». apoyo a la revolución sandinista en Nicaragua, la oposición a las dictaduras en Chile y Argentina, la participación en congresos de intelectuales de izquierdas, o la colaboración con la prensa socialista. Relaciona esta actividad con la visión socialista del futuro y destaca su amistad con Pablo Neruda, considerado entonces amigo de la URSS.

Asimismo, Teitelboim hace hincapié en el papel de los libros de Cortázar en la lucha revolucionaria y cuenta la historia del escritor uruguayo Fernando Butassoni, quien, al visitar las trincheras de los sandinistas, encontró un gastado ejemplar de Rayuela. Al parecer, los combatientes leían Rayuela en voz alta, lo que permite a Teitelboim afirmar que al escritor «le gustaba estar en la trinchera, en trincheras emplazadas donde fuera necesario y con el arma suya más efectiva, su creación» (Teitelboim, 1984a: 5I). El texto rehabilita en los ojos de los socialistas a Oliveira, criticado por Terterián en 1974. Teitelboim (1984a: 55) escribe que Oliveira hablaba de «defender con la vida las ideas que redimen a los pueblos», lo que en la traducción al ruso se refuerza y se convierte en el hecho de afirmar la necesidad de esta acción (Teitelboim, I984b: I78). Teitelboim no menciona el Libro de Manuel, pero cita la frase de Cortázar sobre 62. Modelo para armar, a la que el escritor consideraba como una hija fea, pero secretamente preferida (ib.: I79).

Como se ha dicho, debido a la reputación de Teitelboim como escritor ideológicamente afín, la publicación de este artículo repercutió en la traducción al ruso de dos novelas cortazarianas: 62/ Modelo para armar en 1985 y Rayuela en I986. El escrito de Teitelboim fue publicado en agosto y ya en octubre el periodista de la revista Latinskaya América comentaba la preparación de la edición de Rayuela en ruso en su entrevista

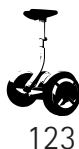


a Marcos Aguinis² (Latinskaya Amérika, I984: I2I). La novela 62/Modelo para armar, a su vez, apareció ya en r985 en la recopilación de obras de Cortázar, editada en 1985 por la editorial Ráduga $^{22}$ [Arcoíris]. Dicha edición de 50.000 ejemplares incorporaba una recopilación de relatos, incluido «Un pequeño paraíso» ${ }^{23}$ de $U n$ tal Lucas en traducción de Pável Grushkó, y la traducción de la novela 62/Modelo para armar (i968) hecha por Evguenia Lysenko.

Estéticamente esta novela experimental «es una especie de prolongación o de brote» (Cortázar, 20I2: vol. 4, 54) del capítulo 62 de Rayuela. Después de su publicación, Cortázar escribía a Graciela de Sola que esta obra era un libro a contrapelo no solo para el lector sino sobre todo para el propio autor, «puesto que entraña una tentativa de narrar contra la narración misma, es decir trata de captar conjuntos en vez de seguir linealmente una acción» (Cortázar, 200o: vol. 2, I265). La publicación rusa estaba acompañaba del prefacio ideológicamente afín al régimen soviético «Julio Cortázar: juego de verdad» ${ }^{24}$ de Terterián (1985). El prefacio contiene múltiples alusiones al compromiso político de Cortázar (Terterián, I988: 443, 447, 451, 459, 46r) ${ }^{25}$. En cuanto a su obra, la hispanista afirma que la narración de Cortázar reflejaba su compromiso social, aunque-debido al uso de las imágenes, metáforas y asociaciones - de manera menos evidente que en sus ensayos.

2I Marcos Aguinis fue nombrado secretario de Cultura de la Nación en Argentina una vez establecida la democracia en 1983 .

22 «Радуга».

23 En 1985 y 1986 el traductor Rostislav Rybkin incluyó su traducción del mismo relato en dos antologías de cuentos publicadas por las editoriales Pravda e Inostrannaya literatura.

24 «Хулио Кортасар: Игра взаправду».

${ }_{25}$ El texto data de 1985 , pero de aquí en adelante se cita según su reedición dentro de la recopilación de estudios de Terterián en 1988.
Estas afirmaciones harán eco en el prefacio de Terterián a la traducción de Rayuela de 1986. Esta novela, donde Cortázar desarrolló plenamente el tema de la búsqueda metafísica y de la destrucción del lenguaje convencional, rompe los moldes narrativos y lingüísticos. El personaje de Rayuela no se conforma con el mundo de las ideas prefabricadas y con las respuestas listas «de la sociedad x o de la sociedad $\mathrm{z}$, de la ideología a o de la ideología b» (Cortázar, 20I3: 22) y cuestiona el camino de la civilización judeocristiana en general. A pesar de la escala de las búsquedas metafísicas de Oliveira (o debido a ello), este personaje sigue siendo un individualista y toda su investigación se concentra en su propio destino, sus penas y su felicidad individual. Estos aspectos de la obra obstaculizaban su introducción en el campo literario soviético. Cabe subrayar que Rayuela, cuya publicación marcó la consagración de Cortázar en el resto del mundo, fue mencionada en varios resúmenes de la crítica literaria latinoamericana preparados para Inostrannaya literatura. Por ejemplo, ya al año siguiente después de la primera traducción rusa de Cortázar, en I97ı, Bylínkina preparó para Inostrannaya literatura un resumen de un artículo de Cuadernos de cultura donde se destacaba la influencia de Cortázar en toda la literatura argentina progresista (RGALI, I97Ia: 4-5) y el papel positivo de la estructura innovadora de Rayuela:

Даже необычное, трудно приемлемое построение романа «Игра в классикиы» ( 1963 ), взломавшее традиционную структуру романа (свободное обращение с местом и временем действия) сыграло в целом положительную роль, позволив литераторам более свободно выбирать художественные формы и приемы, чтобы, - как парадоксально это ни звучит, более свободно изображать окружающую 
буржуазную действительность. [Hasta la construcción inusual, difícilmente aceptable de la novela Rayuela [NB: dos versiones de traducción del título] (I963), que rompió la estructura tradicional de la novela (tratamiento libre del lugar y del tiempo de la acción), en general, desempeñó un papel positivo, permitiendo a los literatos escoger libremente las formas y las técnicas artísticas para, aunque parezca paradójico, describir con más libertad la realidad burguesa que los rodea]. (ib.:5)

Sin embargo, esta reseña no tuvo efecto y la novela no llegó a traducirse al ruso hasta 1986 después de su valoración positiva por parte del comunista chileno Teitelboim, considerado amigo de la URSS. La primera edición rusa de Rayuela se imprimió en I986 por la editorial Judózhestvennaya literatura con una tirada de I00.000 ejemplares. El texto de la traducción hecho por Liudmila Siniánskaya se acompañó del prefacio de Terterián que daba una interpretación ideológicamente afín a la figura y obra de Cortázar.

\section{CONCLUSIONES}

El control estatal en el ámbito de la traducción y circulación de literatura traducida en la URSS formaba parte de la política cultural y representaba una de las herramientas más eficaces de violencia simbólica que permitía legitimar el régimen y crear un imaginario de Occidente afín a la metanarrativa comunista. Su mecanismo, más que una mera censura restrictiva, representaba la imposición al campo literario de ciertas reglas del juego dictadas por el campo de poder con el fin de fomentar la ideología y el discurso dominante. En el caso de Julio Cortázar pudimos observar que su introducción en el campo literario soviético fue facilitada por su postura política de izquierdas, pero el imagi- nario de su obra fue manipulado por medio de las reescrituras en el sentido de Lefevere (1992).

Su introducción en el campo literario soviético fue preparado a través de reiteradas menciones en la prensa a su compromiso social que proporcionaban una reescritura historiográfica de su imaginario. Asimismo, la mayor parte de las traducciones de la obra de Cortázar de la época soviética son textos bastante cortos minuciosamente seleccionados e incluidos en revistas, periódicos y antologías; solo una cuarta parte de ellas corresponde a ediciones enteramente compuestas por la obra cortazariana. En estas publicaciones se daba preferencia a los ensayos dedicados a la lucha contra el capitalismo y las dictaduras latinoamericanas y a los relatos que podían tener una interpretación social. Todas las traducciones de ficción, por cortas que fueran, iban acompañadas de artículos críticos que proponían una reescritura de la obra, subrayando el compromiso político del autor, el lado realista de su prosa y el subtexto social en la temática de los textos. Como resultado, el lector soviético recibía una imagen ideológicamente condicionada de la figura y obra de Cortázar.

Todas estas reescrituras fueron producidas por los profesionales del mundo literario cuyos habitus fueron estructurados por el campo literario soviético y su relación con el campo de poder. Sin embargo, a pesar del fuerte control estatal, el campo literario soviético mantenía cierta plasticidad. En su teoría de la manipulación del canon literario, André Lefevere (I992: I3) argumenta que los editores, traductores y críticos literarios de cierto sistema literario pueden escoger adaptarse a las reglas del sistema y devenir guardianes de su ideología y poética dominantes u oponerse al orden establecido. En el caso de la consagración de Cortázar en la URSS vemos que estos agentes no se oponían directamente, pero algunos utilizaban las reglas 
del juego del campo literario para promover los autores y obras que no se inscribían orgánicamente en el discurso y poética dominantes. Estos agentes son lo que Samantha Sherry (2012: 60-6I) llama agentes dobles, que tienen a la vez el habitus poético occidental, formado debido a su posición privilegiada que le daba acceso a viajes y contactos con los escritores extranjeros, y el habitus político soviético, impuesto por el campo de poder.

Muchas obras de Cortázar del período metafísico o estético se tradujeron al ruso gracias a los mediadores culturales, sobre todo de Bylínkina y Braguinskaya, que insistieron en su edición en las fichas de lectura preparadas para las editoriales y en las reuniones del equipo editorial, argumentando su postura según las reglas impuestas por el espacio social soviético.

Asimismo, en algunos casos las nuevas traducciones aparecían pocos meses después de artículos críticos sobre Cortázar o de otros textos suyos de índole social o política, que justificaban la publicación poniendo de relieve la afinidad ideológica del autor. De esta manera los críticos preparaban la justificación ideológica de la edición de otras de sus obras sin subtexto social o que resultaban demasiado innovadoras en el plano narrativo. La opinión de los intelectuales de izquierdas que la URSS quería atraer a su lado también tenía mucho peso. Así, la traducción de las novelas Rayuela y 62/Modelo para armar se aseguró con la aparición de un artículo elogioso de Volodia Teitelboim, comunista chileno considerado amigo de la Unión Soviética, mientras que la novela Libro de Manuel de temática más politizada pero no mencionada en el artículo no se tradujo al ruso.

RECIBIDO EN JULIO DE 2018 ACEPTADO EN FEBRERO DE 2019 VERSIÓN FINAL DE MARZO DE 2019

\section{REFERENCIAS BIBLIOGRÁFICAS}

BAER, Brian James (2016): Translation and the Making of Modern Russian Literature, New York: Bloomsbury Academic.

BAgnó, Vsévolod (I999): «Mesto pod nazvaniem Cortázar», en Julio Cortázar, Vratá neba, San Petersburgo: Ámfora, 5-30.

BAI, Evgueni (I984): «Borez za svobodu», Izvestia, I8 de febrero, 4 .

Borísova, Alla (2016): Entrevista telefónica el Ig/II/2OI6, San Petersburgo.

Bourdieu, Pierre (I99I): «Le champ littéraire», Actes de la recherche en sciences sociales, 89, 3-46.

Bourdieu, Pierre (I996): Raisons pratiques: sur la théorie de l'action, Paris: Éditions de Seuil.

Bourdieu, Pierre y Loic J. D. Wacquant (I992): "The Practice of Reflexive Sociology», en $A n$ Invitation to Reflexive Sociology, Chicago: The University of Chicago Press, 218-26o.

Braguíns Kaya, Ella (i97i): "Julio Cortázar i ego rasskazy», en Julio Cortázar, Drugoe nebo, Moscú: Judózhestvennaya literatura, 5-20.

Bylínkina, Margarita (I970): «Dve novelly», Inostránnaya literatura, I, 7-8.

Bylínkina, Margarita (I97I): «Predislovie: Julio Cortázar "Material dlia vayania"», Latinskaya Amérika, 2, I3I-I33.

Bylín Kina, Margarita (2005): Vsegó odín vek, Moscú: Grifón.

Cortázar, Julio (1984): «Julio Cortázar: eta revolutsia i est kultura", Latinskaya Amérika, 6, ıо4-ıाо.

Cortázar, Julio (2000): Cartas en 3 tomos: 1937-1963, 1964-1968, I968-1983, ed. por Aurora Bernárdez, Buenos Aires: Alfaguara.

Cortázar, Julio (20I2): Cartas en 5 tomos: 1934-I954, I955-I964, I965-I968, I969-I976, I977-I984, ed. por Aurora Bernárdez y Carles Alvarez Garriga, 2.a ed., Madrid: Alfaguara.

Cortázar, Julio (20I3): Clases de literatura: Berkeley, I980, Madrid: Alfaguara.

Evtushenko, Evguéni (I980): «Dialog v masterskoi pisátelia», Literatúrnaya gazeta, 6 de febrero, I5.

Foucault, Michel (1980): Power/Knowledge. Selected Interviews and Other Writings 1972-1977, New York: Pantheon Books.

Fuentes, Carlos (2004): Julio Cortázar por Carlos Fuentes, <http://www.lamaquinadeltiempo.com/ cortazar/fuentes.htm> [consulta: $\mathrm{I} 6-\mathrm{V}-20 \mathrm{I} 7]$. 
Korionov, Vitali (1985): «Dvizhenie solidárnosti: Shíritsia podderzhka spravedlivoi borbý naródov Latinskoi Amériki», Pravda, 2I de enero, 5.

Lefevere, André (1992): Translation, Rewriting, and the Manipulation of Literary Fame. London; New York: Routledge.

Lyotard, Jean-François (I979): La Condition postmoderne: rapport sur le savoir, Paris: Éditions de Minuit.

«Marcos Aguinis: "Kultura - resultat tvórChestva vsegó NARodA"», Latinskaya Amérika, I984 (IO), II5-I22.

Medvedenko, Anatoli (1969): «Kongréss pisátelei Latinskoi Amériki», Literatúrnaya gazeta, 27 de agosto, 3 .

Ógneva, Elena (1978): «Fantastícheskoe po Cortázaru», Inostránnaya literatura, 8, 265-267.

Ospovat, Lev (I976): «Poiski i otkrytia Julio Cortázara», en Julio Cortázar, Vyigryshi. Póvesti i rasskazy, Moscú: Progress, 5-24.

«Predislovie: My tak lúbim Glendu», Literatúrnaya gazeta, I5 de febrero de $1984, \mathrm{I} 5$.

Rama, Angel (I98I): «El 'boom' en perspectiva», en David Viñas (ed.), Más allá del «boom»: literatura y mercado, México: Marcha, 5I-IIo.

Rgali (I966): FONDO I573, lista 4, dossier 334.

RgALI (I967): FONDO I573, lista 5, dossier 739.

RGALI (I968): FONDO 6I3, lista IO, dossier 5269.
RGALI (I97IA): FONDO 1573, lista 4, dossier 338.

RgALI (I971B): Fondo 613, lista Io, dossier 5347.

Schipágina, Liudmila (I984): "Matagalpa jóchet mira», Pravda, I6 de abril, 6.

Sherbakov, Konstantin (I979): «Chilíiskaya kultura zhivá!», Literatúrnaya gazeta, I6 de mayo, 9.

Sherry, Samantha (20I2): "Censoring Translation in the Stalin and Khrushchev Soviet Era». University of Edinburgh.

Teitelboim, Volodia (i984a): «Julio Cortázar», Casa de las Américas, I45-I46, 47-58.

Teitelboim, Volodia (1984b): «Putí i nadezhdy Julio Cortázara», Inostránnaya literatura, 8, I73-I79.

Terterián, Inna (I974): «Noveishi paradoksalist», Inostránnaya literatura, 7, 226-234.

Terterián, Inna (I982): «Pylaushi pépel kostrá », Literatúrnaya gazeta, 29 de septiembre, 15 .

Terterián, Inna (I984): «Predislovie: Nochnaya shkola», Literatúrnaya gazeta, I9 de septiembre, I5.

Terterián, Inna (I985): «Julio Cortázar: Igra vzapravdu», en Julio Cortázar, 62. Model dlia zborki. Rasskazy, Moscú: Raduga, 3-2I.

Terterián, Inna (I988): Chelovek mifotvoriashi. O literature Ispanii, Portugalii i Latinskoi Amériki, Moscú: Sovetski pisátel.

Veller, Mijail (2003): Dolina ídolor, San Petersburgo: Parol.

ZMéEv, Serguéi (I979): «Vstuplenie. Apocálipsis Solentiname», Inostránnaya literatura, 6, I83-I84. 